\title{
Study of Risk Factors and Their Effect on Outcome in Stroke
}

\author{
Sharanabasappa Basawaraj Nandyal ${ }^{1}$, Nanda Sharanabasappa Nandyal ${ }^{2}$ \\ ${ }^{1}$ Department of Medicine, Mahadevappa Rampure Medical College, Kalaburgi, Karnataka, India. \\ ${ }^{2}$ Department of Anaesthesia, Mahadevappa Rampure Medical College, Kalburgi, Karnataka, India.
}

\section{ABSTRACT}

\section{BACKGROUND}

Stroke is a life-threatening neurological disorder. Incidence in India is 50 to 300 per lakh and is high in western countries. Recently, increase in the number of stroke patients is due to sedentary lifestyle, but mortality and morbidity is decreased with early diagnosis and treatment of the causative factor. Prediction of various conditions causing stroke and its impact on prognosis and course of the disease is important. It will help to recognise the patients who are at risk and provides proper intervention for better prognosis and outcome.

\section{METHODS}

This is an observational study carried out in subjects with acute stroke admitted in Basaveshwara Hospital and followed till discharge for a period of two years. 60 cases were selected, and all details were recorded. All cases of acute stroke diagnosed by clinical features and computed tomography wherever necessary were included in the study. Patients with TIA, neurological deficit \& history of trauma were excluded.

\section{RESULTS}

Of the total of 60 patients, 40 were males and 20 were females. Among 40 male patients, 18 patients ( $45 \%)$ died, $6(15 \%)$ recovered completely, $6(15 \%)$ recovered partially, 10 (25\%) did not improve. Among 20 female patients, 6 (30\%) expired, 3 (15\%) recovered completely, 5 (25\%) recovered partially, 6 (30\%) did not improve.

\section{CONCLUSIONS}

Older patients had a higher mortality rate from stroke than younger patients. Complete recovery was better in younger patients than in older patients. Mortality rate was higher in patients with risk factors and recovery rate was better in patients without risk factors. Mortality was higher in patients who were unconscious on admission.

\section{KEY WORDS}

Predictors, Stroke, Recovery, Mortality
Corresponding Author: Dr. Nanda Sharanabasappa Nandyal Sri Nandyal Hospital, Beside Santraswadi City Bus Stop, Darga Road, Kalaburgi- 585105, Karnataka, India.

E-mail: nandyalnanda@gmail.com

DOI: $10.14260 /$ jemds/2020/701

How to Cite This Article:

Nandyal SB, Nandyal NS. Study of risk factors and its effects on outcome in stroke. J Evolution Med Dent Sci 2020;9(43):31963199, DOI: 10.14260/jemds/2020/701

Submission 31-03-2020,

Peer Review 19-09-2020,

Acceptance 25-09-2020,

Published 26-10-2020.

Copyright (C) 2020 Sharanabasappa Basawaraj Nandyal, et al. This is an open access article distributed under Creative Commons Attribution License [Attribution 4.0 International (CC BY 4.0)] 


\section{BACKGROUND}

Stroke is one of the life-threatening neurological disorders. Incidence in India is 50 to 300 per lakh and is high in western countries. Recently increase in the number of stroke patients is due to sedentary lifestyle but mortality and morbidity is decreased with early diagnosis and treatment of the causative factor. Prediction of various conditions causing stroke and its impact on prognosis and course of the disease is important. It will help to recognise the patients who are at risk and provide proper intervention for better prognosis and outcome. Stroke is defined as an acute onset of a non-convulsive and focal neurological deficit remaining for more than 24 hours. The concept of therapeutic window in this indicates the short time after stroke in which some viable brain tissue can be salvaged by proper and timely intervention. In this study, I propose to present my observation regarding "Study of Risk factors and Its Effects on Outcome in Stroke" among the patients admitted in our hospital. Study is only during hospital stay as study is regarding the outcome of stroke in the form of recovery, morbidity and mortality. Apoplexy was identified as cause of death before Hippocrates. ${ }^{1}$ Paracelsus (1493 - 1541) compared apoplexy with lightning stroke. ${ }^{2}$ Probably the first attempt to discriminate between cerebral haemorrhage and cerebral infarction was made by Morgagni (1692 - 1771) of Padua who was taught by Valsalva. He studied cerebrovascular disease extensively and proved by autopsy that the lesion in the brain will be in opposite side of paralysis. $^{3}$ William Sen House Kirles (1825) was the first to give description of cerebral embolism. Panam first proposed that debris from atherosclerotic plaques can cause emboli. This view became accepted and yellow softening described by Ring Fleisch in $1873^{4}$ was agreed to be due to preceding obstruction of the supplying artery, usually by a clot and cerebral thrombosis was established as an important cause of stroke. In $20^{\text {th }}$ century, cerebral haemorrhage, thrombosis and embolism were identified as cause of stroke and replaced the term apoplexy and hemiplegia. Godfrey Hounsefield in 1972 invented computed tomography (CT) scan and has revolutionized the diagnosis and treatment of stroke ${ }^{5}$.

According to World Health Organization (WHO) stroke is defined as acute development of focal or global disturbance in cerebral function with signs and symptoms lasting for more than 24 hours without any cause other than vascular origin. ${ }^{6}$ In this mortality increases with advanced age about a quarter occur below the age of 65 and about a half below the age of 75 . The standardized death rate attributed to stroke varies considerably between countries.

\section{METHODS}

This observational study was done in M.R. Medical College and Basaveshwara Teaching and General Hospital. Study got approval from ethical committee. The basis of sample size and selection is done depending on previous literatures, pilot study and past clinical experience. Written valid consent is taken from patients under study and their relatives (in unconscious patients). Patients who fulfil the inclusion criteria are taken in study. Those who do not fulfil the specified criteria are excluded. 60 cases of acute stroke patients and followed up till discharge are studied during 2 years of period. 60 cases of acute stroke patients (40 male and 20 female) admitted in Basaveshwara General and Teaching Hospital, M. R. Medical College, Kalburgi.

\section{Inclusion Criteria}

All cases of acute stroke diagnosed by typical signs and symptoms and computed tomography.

\section{Exclusion Criteria}

All cases of TIA.

Old cases of stroke.

Neurological deficit with history of trauma.

Cases of stroke where diagnosis is not definite both clinically as well as on CT scan.

\section{Investigations}

Routine blood and urine.

Fasting and postprandial blood glucose level.

Computed tomography (CT scan).

Electrocardiogram.

Chest X-ray PA view.

2D echo with colour Doppler, blood urea, serum creatinine and lipid profile wherever necessary.

\author{
Outcomes Studied \\ Death. \\ Complete recovery. \\ Partial recovery. \\ No recovery (no improvement of neurological deficit).
}

\section{Statistical Analysis}

Data is collected using standard questionnaire, clinical examinations and investigations after satisfying the inclusion criteria, entered in excel sheet and analysed by using SPSS Software version 20. Descriptive statistic like percentage is used to describe data. Multi variate logistic regression models were used to estimate the impact of possible determinants of stroke severity at admission. Differences between groups and effect of patient characteristics on clinical outcome were assessed by chi-square test. Statistical test were significant when $\mathrm{p}$-value $<0.05$.

\section{RESULTS}

\begin{tabular}{|ccccccc|}
\hline $\begin{array}{c}\text { Age in } \\
\text { Yrs. }\end{array}$ & Total & Dead & $\begin{array}{c}\text { Complete } \\
\text { Recovery }\end{array}$ & $\begin{array}{c}\text { Partial } \\
\text { Recovery }\end{array}$ & $\begin{array}{c}\text { No. } \\
\text { Recovery }\end{array}$ & $\begin{array}{c}\text { P } \\
\text { Value }\end{array}$ \\
$<30$ & 2 & $1(50 \%)$ & $1(50 \%)$ & 0 & 0 & \\
$31-40$ & 6 & 0 & $4(66.66 \%)$ & 0 & $2(33.33 \%)$ & \\
$41-50$ & 12 & $8(66.66 \%)$ & 0 & 0 & $4(33.33 \%)$ & $<0.05$ \\
$51-60$ & 19 & $8(42.10 \%)$ & $1(5.56 \%)$ & $6(31.57 \%)$ & $4(21.05 \%)$ & \\
$61-70$ & 16 & $4(25 \%)$ & $3(18.75 \%)$ & $4(25 \%)$ & $5(31.25 \%)$ & \\
$71-80$ & 5 & $3(60 \%)$ & 0 & $1(20 \%)$ & $1(20 \%)$ & \\
\hline \multicolumn{7}{|c|}{ Table 1. Age Distribution and Outcome in Different Age Groups } \\
\hline
\end{tabular}

Of the total 60 patients, 40 were males and 20 were females. In the 40 male patients 18 patients ( $45 \%$ ) died, 6 (15 $\%$ ) recovered completely, 6 (15\%) recovered partially, 10 (25 
\%) not improved. Among 20 female patients 6 (30\%) expired, 3 (15\%) recovered completely, 5 (25\%) recovered partially, $6(30 \%)$ not improved.

\section{Headache}

There were 30 patients who gave history of headache. Among them, 15 patients $(50 \%)$ died, 3 patients $(10 \%)$ had complete recovery and partial recovery each and $9(30 \%)$ had no recovery. Of the 30 patients who presented without headache, 9 (30\%) died, 6 (20\%) recovered completely, 8 (26.66\%) recovered partially, 7 (23.33\%) not improved.

\begin{tabular}{|cccccc|}
\hline & $\begin{array}{c}\text { Un- } \\
\text { Conscious }\end{array}$ & Drowsy & Stuporous & $\begin{array}{c}\text { Fully } \\
\text { Conscious }\end{array}$ & $\begin{array}{c}\text { P } \\
\text { Value }\end{array}$ \\
$\begin{array}{c}\text { Dead } \\
\text { Complete } \\
\text { Recovery }\end{array}$ & $22(91.66 \%)$ & 0 & $1(4.16 \%)$ & $1(4.16 \%)$ & \\
$\begin{array}{c}\text { Partial } \\
\text { Recovery }\end{array}$ & $2(6.44 \%)$ & $4(25 \%)$ & $2(16.66 \%)$ & $3(30 \%)$ & $<0.05$ \\
No Recovery & $7(22.58 \%)$ & $6(50 \%)$ & 0 & $3(30 \%)$ & \\
Total n= 60 & $\mathbf{3 1}(\mathbf{5 1 . 6 6} \%)$ & $\mathbf{1 3}(\mathbf{2 1 . 6 6} \%)$ & $\mathbf{6 ( 1 0 \% )}$ & $\mathbf{1 0}(\mathbf{1 6 . 6 6} \%)$ \\
\hline \multicolumn{5}{|c|}{ Table 2. Level of Consciousness at Admission and Outcome } \\
\hline
\end{tabular}

\section{Convulsions}

Out of 60 patients, 16 (26.66\%) gave history of convulsions, 5 (31.25\%) died, 1 (6.25\%) recovered completely, 5 (31.25\%) recovered partially and 5 (31.25 \%) not improved. Of the 44 patients who were presented without convulsions 19 (36.3\%) died, 8 (18.18\%) recovered completely, 6 (13.63\%) recovered partially 11 (25\%) not improved.

\section{Hypertension}

Of the 60 patients, 35 (58.33\%) gave history of hypertension. Of the 35 patients who presented with history of HTN, 21 (60 $\%)$ died, 2 (5, $71 \%$ ) recovered completely, 8 (22.85\%), recovered partially 4 (11.42\%) not improved. Of the 25 patients who presented without history of HTN, 2 (12\%) died, $7(28 \%)$ recovered completely, 3 (12\%) recovered partially, 12 (48\%) not improved.

\section{Diabetes}

Of the 60 patients, $19(31.66 \%)$ had diabetes. Of the 19 patients of diabetes, $8(42.10 \%)$ died, 4 (21.05\%) recovered completely, 4 (21.05\% recovered partially) 3 (15.78\%) not improved. Of the 41 patients who had no history of diabetes, $16(31.02 \%)$ died, 5 (12.19\%) recovered completely, 7 (17.07 $\%)$ recovered partially 13 (31.70 \%) not improved.

\section{Ischemic Heart Disease (IHD)}

Of the 60 patients, 10 (16.66\%) gave history of ischemic heart disease. Of the 10 patients who had past history of ischemic heart disease, 6 (60\%) died, 2 (20\%) recovered partially and $2(20 \%)$ not improved. Of the 50 patients who gave no history of IHD, 18 patients (36\%) died, 9 (12 \%) recovered completely, 9 (18\%) recovered partially and 14 (28\%) not improved.

\section{Aspiration}

18 patients ( $30 \%$ ) of the 60 patients developed aspirations. Of the 18 patients of aspiration, 13 (72.22\%) died, 11 (5.55 $\%)$ recovered partially 5 (22.22\%) not improved. Of the 42 patients without aspiration, 11 (26.19\%) died, 9 (21.42\%) recovered completely, $10(23.80 \%)$ recovered partially 12 (28.57\%) not improved.

\begin{tabular}{|cccc|}
\hline & Smokers & Non-Smokers & P Value \\
Dead & $15(51.72 \%)$ & $9(29.03 \%)$ & \\
Complete Recovery & $6(20.68 \%)$ & $3(9.67 \%)$ & $<0.05$ \\
Partial Recovery & $2(6.89 \%)$ & $9(29.03 \%)$ & \\
No Recovery & $6(20.68 \%)$ & $10(32.25 \%)$ & \\
Total & $\mathbf{2 9}$ & $\mathbf{3 1}$ & \\
\hline \multicolumn{4}{|c|}{ Table 3. Frequency of Smoking and Outcome } \\
\hline
\end{tabular}

\begin{tabular}{|cccc|}
\hline & Tobacco Chewer & $\begin{array}{c}\text { Non-Tobacco } \\
\text { Chewer }\end{array}$ & P Value \\
\hline Dead & $8(53.33 \%)$ & $16(35.55 \%)$ & \\
Complete Recovery & $3(20.00 \%)$ & $6(13.33 \%)$ & $<0.05$ \\
Partial Recovery & $1(6.66 \%)$ & $10(22.22 \%)$ & \\
No Recovery & $3(20.00 \%)$ & $13(28.88 \%)$ & $\mathbf{4 5}$ \\
\hline Total & $\mathbf{1 5}$ & Table 4. Frequency of Tobacco Chewing and Outcome \\
\hline \multicolumn{2}{|r}{}
\end{tabular}

\begin{tabular}{|cccc|}
\hline & Alcoholics & Non-Alcoholics & P Value \\
Dead & $6(60.00 \%)$ & $18(36 \%)$ & \\
Complete Recovery & $1(10.00 \%)$ & $8(16 \%)$ & $<0.05$ \\
Partial Recovery & $2(20.00 \%)$ & $9(18 \%)$ & \\
No Recovery & $1(10.00 \%)$ & $15(30 \%)$ & $\mathbf{5 0}$ \\
\hline Total & $\mathbf{1 0}$ & Table 5. Alcohol Consumption and Outcome \\
\hline \multicolumn{4}{|c}{} \\
\hline
\end{tabular}

\section{DISCUSSION}

Here maximum deaths occurred in the age group of $41-50$ yrs. (66.66\%) followed by the $71-80$ yrs. (60\%) age group. No death occurred in the 31 - 40 yrs. age group. Complete recovery occurred in younger patients. $50 \%$ of patients in the less than $30 \mathrm{yrs}$. age group and $66.66 \%$ of patients in the 31 40 yrs. age group. Complete recovery occurred in less number of patients in older age group i.e. $5.26 \%$ in 51 - $60 \%$ years age group, $18.75 \%$ in the $62-70$ years and no patients of $71-80$ $\%$ years had complete recovery. Our findings of least mortality in younger patients and maximum mortality in the older patients in consistent with the studies of Glynn and Carter. ${ }^{7}$

Out of the 60 patients admitted with acute cerebrovascular accident, 40 patients $(66.66 \%)$ were males and the remaining 20 patients were females. In the present study, death from stroke was higher in males (45\%) while it was $30 \%$ in females. Complete recovery was equal in both the sexes (15\%) our findings consistent with the findings of Henon et al who found mortality was higher in male sex $25 .{ }^{8}$ 30 patients (50\%) had headache on admission. Death was more common in patients who had headache. $50 \%$ of the patients who had headache died while $30 \%$ of the patients who were admitted without history of headache died. Our findings were consistent with findings of Shefama et al, who also found that patients with headache at a great chance of dying than patients without headache ${ }^{9} 28$ patients $(28.33 \%)$ gave history of vomiting. In the present study, death was higher in patients with vomiting $56.5 \%$ of patients with vomiting died while $28.72 \%$ of the patients without vomiting died.

Complete recovery was much higher in patients without vomiting, $21.62 \%$ of the patients without vomiting had complete recovery, while only $4.34 \%$ of patients with vomiting had complete recovery. The findings of greater 
mortality in patients with vomiting are consistent with findings of Aring and Meritt. ${ }^{10}$

Of the 60 patients, 29 patients $(48.33 \%)$ were smokers. Mortality rate was more in smokers (51.72\%) and less in nonsmokers $(26.08 \%)$. These findings of higher mortality in patients who smoke is consistent with study of Rastenyte et al11 32. Tobacco chewing: 15 patients (25\%) were tobacco chewers. In the present study we found mortality was higher in patients who chewed tobacco than those who did not chew tobacco. $43.33 \%$ of the patients who chewed tobacco expired, while $35.55 \%$ of the patients who did not chew expired. Of the $60 \%$ patients admitted with acute cerebrovascular stroke 28 (46.66 \%) had infarction while 32 (53.33\%) had haemorrhage. Here, patients with haemorrhage showed more mortality (50\%), than patients of infarction (28.57 \%). $50 \%$ of the patients with haemorrhage died while $28.57 \%$ of the patients with infarction died. Complete recovery was more common in the patients with infarction. $25 \%$ of the patients infarction had complete while $6.25 \%$ of the haemorrhage had complete recovery.

\section{CONCLUSIONS}

Mortality rate was higher in older patients and in patients with history of vomiting, headache, hypertension, diabetes, smoking, ischemic heart disease (IHD), tobacco chewing, alcohol consumption, patients with ECG abnormalities, unconsciousness on admission, aspiration and haemorrhage. Mortality rate was less, and recovery was good in young patients and in patients with no history of vomiting, headache, hypertension, diabetes, smoking, ischemic heart disease (IHD), tobacco chewing, alcohol consumption, patients with ECG abnormalities, unconsciousness on admission, aspiration, infarction and outcome was good. Strong risk factors for the mortality in stroke were unconscious on admission, with aspiration, old age, headache, vomiting, with co-morbid conditions like hypertension, ischemic heart disease, diabetes, cerebral haemorrhage and convulsions. My inference from this study is that if we decrease the incidence of various risk factors by lifestyle modification and control of co-morbid conditions, we can reduce the incidence of stroke, mortality and morbidity with better outcome.
Data sharing statement provided by the authors is available with the full text of this article at jemds.com.

Financial or other competing interests: None.

Disclosure forms provided by the authors are available with the full text of this article at jemds.com.

\section{REFERENCES}

[1] Wylie CM. Epidomology of Cerebrovascular disease. Chap- 9. Part-1. In: Bruyn GW, Vinken PJ, eds. Hand book of clinical neurology. Amsterdam: North-Holland Publishing Company 1972: p. 183.

[2] Carter AB. Clinical aspectes of cerebral infarction. Chap12. Part 1. In: Bruyn GW, Vinken PJ, eds. Hand book of clinical neurology. Amsterdam: North-Holand Publishing Company 1972.

[3] Jain S, Maheshwari MC. Cerebrovascular diseases: a review of the Indian experience in the last 35 years. Neuroepidemiology 1986;5(1):1-16.

[4] Macewen W. An address on the surgery of the brain and spinal cord. Br Med J 1888;2(1441):302-9.

[5] Eisenberg RL. Radiology-an illustrated history. Mosby Year Book 1992: p. 467 \& 473.

[6] Bontia R. Epidemology of stroke. Lancet 1992;339(8789):342-4.

[7] Glynn AA. Vascular diseases of the Nervous system; a series of 315 cases. Br Med J 1956;1(4977):1216-9.

[8] Henon H, Godefroy O, Leys D, et al. Early predictors of death and disability after acute cerebral ischemic event. Stroke 1995;26:392-8.

[9] Schafama S. On the differential diagnosis between cerebral haemorrhage and infarction. Journal of Neurological Sciences 1968;7(1):83-8.

[10] Aring CD, Merritt HH. Differential diagnosis between cerebral hemorrhage and cerebral thrombosisa clinical and pathologic study of 245 cases. Archieves of Internal Medicine 1935;56(3):435-56.

[11] Rastenyte D, Tuomilehto J, Domarkiene S, et al. Risk factors for death from stroke in middle-aged Lithuanian men: results from a 20-year prospective study. Stroke 1996;27(4):672-6. 